\title{
STUDI AKSELERASI PERTUMBUHAN SEKTOR PERIKANAN DI WILAYAH PESISIR INDONESIA
}

\author{
Dr.Ernawati,SE.,M.i' ${ }^{1)}$, Wali Aya Rumbia,SE.,M.Si' ${ }^{2}$, Irwandi'), M.Rajib Haslim(4), \\ Muh.Erlan P. 5), dan Rheyna Maulidaro) \\ ${ }^{1,2}$ Staf Pengajar FEB Universitas halu oleo \\ 3,4,5,6 Mahasiswa Jurusan IE FEB UHO \\ Jl. HEA Mokodompit Kampus Bumi Tridharma Anduonohu Kendari \\ email: erna_unhalu@yahoo.com
}

\begin{abstract}
ABSTRAK
Kontribusi satelite kelautan dan perikanan pada beberapa tahun cenderung mengalami penurunan, yaitu sebesar 4,33 persen pada tahun 2009 , menurun menjadi 4,25 persen pada tahun 2010; dan 4,23 persen untuk tahun 2012. Tren penurunan kontribusi tersebut perlu terus ditangani oleh pemerintah sebagai upaya mempertahankan dan meningkatkan kelangsungan pengelolaan sumberdaya kemaritiman dalam jangka panjang. Diharapkan pembangunan sektor maritim akan bertumpu pada wilayah pesisir Indonesia sebagai wilayah yang berdekatan langsung dengan perairan laut. Studi ini bertujuan untuk menganalisis apakah sub sektor perikanan mengalami akselerasi pertumbuham di wilayah pesisir Indonesia. Data penelitian merupakan data sekunder yang bersumber dari Kementrian Kelautan dan Perikanan (KKP); dan Badan Pusat Statistik (BPS) Indonesia. Sampel penelitian terdiri 30 kabupaten yang menjadi basis program konservasi perairan Kementrian KKP sejak tahun 2010 dan sebelumnya. Analisis data digunakan yaitu: analisis komparatif pertumbuhan, share; dan tipologi 4 kuadran. Hasil penelitian menunjukkan bahwa sebanyak 7 kabupaten yang diteliti bukan merupakan sektor basis perikanan bagi Indonesia. Secara umum seluruh kabupaten mengalami pertumbuhan dalam sektor perikanan, namun 17 kabupaten diantaranya memiliki pertumbuhan yang lebih rendah dibanding pertumbuhan ekonomi wilayahnya. Pada sisi lain, terdapat kecenderungan penurunan share yang secara total rata-rata pertahun sebesar 3,21 persen. Penurunan share terjadi pada 18 kabupaten. Hasil penelitian juga menunjukkan bahwa hanya 4 kabupaten yang mengalami akselerasi pertumbuhan, bahkan sebanyak 12 kabupaten berada pada wilayah rentan kemunduran pada sub sektor perikanan.
\end{abstract}

Keywords: perikanan, share, akselerasi , basis, pertumbuhan

\section{PENDAHULUAN}

Indonesia memiliki kekayaan alam yang melimpah dan belum terolah secara optimal. Salah satu kekayaan alam tersebut yaitu perairan laut dengan luas yang mencapai dua per tiga dari total luas seluruh wilayah Indonesia. Besarnya potensi tersebut merupakan alasan mendasar untuk mengarahkan kebijakan pembangunan pada sektor kelautan dan atau dalam lingkup yang lebih luas lagi, sektor maritim. Potensi perikanan dan kelautan memang perlu terus digali dan diolah demi kelangsungan jangka panjang.
Perkembangan kontribusi dari beberapa potensi maritim yang telah dikelola disajikan sebagaimana Tabel 1 menunjukkan bahwa perikanan merupakan penyumbang terbesar untuk kelompok satelite kelautan dan perikanan yang telah dikelola. Kontribusi perikanan terhadap penciptaan produk domestik bruto (PDB) Indonesia sebesar 3,15 persen pada tahun 2009. Namun secara konsisten mengalami penurunan sampai tahun 2011, dan kemudian mengalami peningkatan kembali pada tahun 2012. 
Tabel 1

Peranan PDB Satelite Kelautan dan Perikanan Terhadap Penciptaan PDB Indonesia

Periode 2009-2012

\begin{tabular}{lcccc}
\hline Lapangan Usaha & $\mathbf{2 0 0 9}$ & $\mathbf{2 0 1 0}$ & $\mathbf{2 0 1 1}$ & $\mathbf{2 0 1 2}$ \\
\hline 1. Perikanan & $\mathbf{3 , 1 5}$ & $\mathbf{3 , 0 9}$ & $\mathbf{3 , 0 5}$ & $\mathbf{3 , 1 0}$ \\
a. Tangkap & 2,03 & 1,48 & 1,49 & 1,73 \\
b. Budidaya & 1,12 & 1,62 & 1,57 & 1,37 \\
2. Ekstraksi Garam & - & - & $\mathbf{0 , 0 0}$ & $\mathbf{0 , 0 1}$ \\
3. Industri Pengolahan & $\mathbf{0 , 3 0}$ & $\mathbf{0 , 2 8}$ & $\mathbf{0 , 2 7}$ & $\mathbf{0 , 2 6}$ \\
$\quad \begin{array}{l}\text { Kelautan dan } \\
\text { Perikanan }\end{array}$ & & & & \\
$\quad \begin{array}{l}\text { a. Industri Besar dan } \\
\quad \text { Sedang }\end{array}$ & 0,19 & 0,18 & 0,17 & 0,16 \\
$\quad \begin{array}{l}\text { Industri Kecil dan } \\
\quad \text { Rumah Tangga }\end{array}$ & 0,12 & 0,11 & 0,10 & 0,10 \\
$\begin{array}{l}\text { 4. Perdagangan Besar dan } \\
\text { Eceran }\end{array}$ & $\mathbf{0 , 8 7}$ & $\mathbf{0 , 8 7}$ & $\mathbf{0 , 8 7}$ & $\mathbf{0 , 8 6}$ \\
$\begin{array}{l}\text { a. Hasil Perikanan } \\
\text { b. Hasil Pengolahan }\end{array}$ & 0,70 & 0,71 & 0,72 & 0,71 \\
$\quad \begin{array}{l}\text { Perikanan } \\
\text { Jasa Wisata Tirta }\end{array}$ & $\mathbf{0 , 0 1}$ & $\mathbf{0 , 0 1}$ & $\mathbf{0 , 0 1}$ & $\mathbf{0 , 0 1}$ \\
\hline Total Kontribusi & $\mathbf{4 , 3 3}$ & $\mathbf{4 , 2 5}$ & $\mathbf{4 , 2 0}$ & $\mathbf{4 , 2 3}$ \\
\hline
\end{tabular}

Sumber: KKP (2014a) hal. 13-14

Pada sisi lain, industri pengolahan kelautan dan perikanan masih memiliki kontribusi yang rendah terhadap PDB, begitupun ekstraksi garam dan jasa wisata tirta. Adapun kontribusi perdagangan dan eceran hasil perikanan maupun pengolahan memberikan kontribusi 0,87 persen pada tahun 2009; dengan kecenderungan kontribusi yang relatif stagnan hingga 2012. Secara total, tampaknya satelite kelautan dan perikanan justru memiliki kontribusi yang cenderung menurun, yaitu ebesar 4,33 persen pada tahun 2009, menurun menjadi 4,25 persen pada tahun 2010; dan 4,23 persen untuk tahun 2012.

Tren penurunan kontribusi tersebut perlu terus ditangani oleh pemerintah sebagai upaya mempertahankan dan meningkatkan kelangsungan pengelolaan sumberdaya kemaritiman dalam jangka panjang. Diharapkan pembangunan sektor maritim akan bertumpu pada wilayah pesisir Indonesia sebagai wilayah yang berdekatan langsung dengan perairan laut. Hasil studi Wibowo (2012) terungkap bahwa terdapat $281 \mathrm{kabupaten} /$ kota yang terletak di wilayah pesisir Indonesia. Pemerintah telah melakukan serangkaian program guna mendorong pertumbuhan ekonomi sekaligus kelestarian wilayah pesisir.

Salah satu upaya yang dilakukan pemerintah yaitu membentuk kawasan konservasi perairan. Hingga akhir tahun 2014 terdapat 103 kawasan konservasi perairan yang dikelola oleh Kementrian Kelautan dan Perikanan yang tersebar pada 31 propinsi. Jumlah ini masih lebih rendah dibanding jumlah kabupaten yang terletak pada wilayah pesisir Indonesia. Beberapa kawasan konservasi telah dikelola lebih dari satu dekade. Dalam Peraturan Menteri Kelautan dan Perikanan No 13 Tahun 2014 dinyatakan bahwa Kawasan Konservasi Perairan adalah kawasan perairan yang dilindungi, dikelola dengan sistem zonasi, untuk mewujudkan pengelolaan sumber daya ikan dan lingkungannya secara berkelanjutan. Dengan demikian pengelolaan sumber daya perikanan secara berkelanjutan diharapkan bertumpu pada kawasan konservasi ini. Kawasan konservasi perikanan juga diharapkan menjadi kawasan yang memiliki akselerasi pertumbuhan pada bidang perikanan.

Oleh karena itu diperlukan suatu kajian apakah kawasan konservasi tersebut merupakan kawasan yang memiliki pertumbuhan yang tinggi pada sub sektor perikanan sekaligus berkontribusi besar terhadap pendapatan domestik kawasan. Tulisan ini bertujuan untuk memberikan gambaran akselerasi pertumbuhan sub sektor perikanan pada kawasan pesisir yang telah diintervensi langsung oleh pemerintah melalui program konservasi perairan. Diharapkan tulisan ini dapat berkontribusi pada kajian pengembangan ekonomi kawasan pesisir untuk mendorong keberlanjutan pertumbuhan ekonomi Indonesia. 


\section{METODE PENELITIAN}

Data penelitian merupakan data sekunder yang bersumber dari Kementrian Kelautan dan Perikanan (KKP); dan Badan Pusat Statistik (BPS) Indonesia. Populasi penelitian terdiri dari 42 kawasan konservasi perairan Kementrian KKP minimal tahun 2010 dan atau telah berjalan sekitar 5 tahun. Berdasarkan pertimbangan ketersediaan data, jumlah sampel penelitian terdiri 30 kabupaten. Analisis data digunakan yaitu: analisis komparatif pertumbuhan, share; dan tipologi 4 kuadran. Data pertumbuhan ekonomi diambil secara langsung dari hasil publikasi BPS berdasarkan harga konstan tahun 2010. Beberapa data share tidak tersedia sehingga diestimasti dengan rumus:

$$
S_{i}=\frac{D_{i} * P D B p}{P D B_{I}} * 100
$$

Atau:

$$
S_{i}=\frac{P D B_{i}}{P D B_{I}} * 100
$$

Keterangan:

$\mathrm{S}_{\mathrm{i}} \quad=$ share sub sektor perikanan

$\mathrm{D}_{\mathrm{i}} \quad=$ distribusi sub sektor perikanan terhadap pembentukan PDB pertanian

$\mathrm{PDB}_{\mathrm{p}}=\mathrm{PDB}$ sektor pertanian

$\mathrm{PDB}_{\mathrm{i}}=\mathrm{PDB}$ sub sektor perikanan

$\mathrm{PDB}_{\mathrm{I}}=\mathrm{PDB}$ Indonesia

Komparasi pertumbuhan dilakukan dengan membandingkan pertumbuhan ekonomi sub sektor perikanan terhadap pertumbuhan ekonomi wilayah/kabupaten. Kriteria pertumbuhan 'tinggi' jika rasio komparasi lebih besar dari 1 (atau $\geq 1$ ); dan sebaliknya jika lebih kecil dari 1 (atau $<1)$. Sementara indikator share diukur dengan peningkatan dan penurunan share sub sektor perikanan selama periode penelitian. Kabupaten yang dianalisi kemudian dipetakan ke dalam IV kuadran berdasarkan nilai komparasi pertumbuhan dan share. Wilayah dengan pertumbuhan tinggi, dan peningkatan share merupakan wilayah yang mengalami akselerasi pertumbuhan di bidang perikanan.
Selanjutnya untuk menentukan apakah kawaan konservasi merupakan sektor basis bagi Indonesia, maka diukur dengan rasio share sub sektor perikanan kawasan terhadap share sub sektor perikanan secara nasional. Suatu kawasan dikatakan sektor basis jika rasio share perikanan kawasan terhadap share Indonesia lebih besar dari 1 (atau $\geq 1$ ).

\section{HASIL DAN PEMBAHASAN}

\section{Struktur Ekonomi Indonesia}

Struktur ekonomi Indonesia sebagaimana Gambar 1 dipimpin oleh sektor tersier yang berada jauh diatas sektor primer maupun sekunder. Sektor tersier merupakan sektor ekonomi yang yang bergerak dalam sektor jasa. Sementara sektor sekunder merupakan sektor yang mengolah bahan baku sektor primer menjadi bahan setengah jadi dan atau barang jadi. Sektor sekunder meliputi sektor manufaktur, listrik, gas dan air bersih, serta bangunan. Adapun Sektor Primer merupakan sektor utama perekonomian yang bersumber dari hasil bumi. Sektor ini meliputi pertambangan primer dan pertanian secara umum (tanaman pangan, perkebunan, kehutanan, perikanan dan kelautan).

Sektor sekunder tampaknya tidak mengalami perubahan berarti sejak tahun 2000; sementara sektor primer lebih berfluktuasi, bahkan menunjukkan trade off terhadap sektor tersier. Ketika sektor tersier ekspansi (berkontribusi tinggi terhadap PDB), sektor primer akan mengalami kontraktif. Kondisi ini konsisten hampir pada seluruh tahun kecuali perubahan dari tahun $2000 \mathrm{ke}$ 2001; dan 2009 hingga 2011. Pada tahun 2000 ke 2001, penurunan share tersier justru diikuti dengan penurunan share sektor primer. Sebaliknya pada masa 2009 hingga 2011 yang menunjukkan ekspansi sektor tersier diikuti ekspansi sektor primer. Kedua rentang periode ini 
merupakan periode masa pulih dari krisis, baik krisis moneter Indonesia maupun krisis keuangan global. Pola ini menunjukkan bahwa pada masa ekonomi stabil, sektor tersier akan mengalami berkembang dengan cepat meninggalkan sektor primer; namun saat ekonomi lesu, sektor primer bersinergi dengan sektor tersier.

Gambar 1 juga menunjukkan bahwa pada masa krisis keuangan global 20062010, sektor primer tetap menunjukkan ekspansif; sebaliknya dengan sektor tersier. Hal ini mengimplikasikan bahwa sektor primer mampu bertahan dari krisis. Dengan demikian sangat tampak bahwa pembangunan perlu bertumpu pada sektor primer yang lebih tahan krisis. Beberapa penyebab dari karakteristik sektor primer, yaitu keberadaan sumber bahan baku yang lebih melimpah dibanding sektor lainnya.

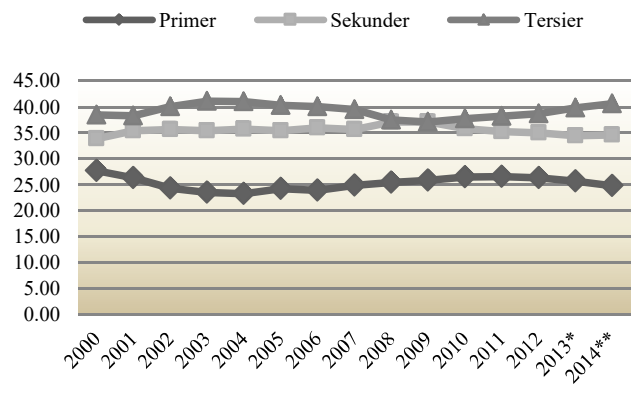

Gambar 1 Struktur Ekonomi Indonesia 2000-2014

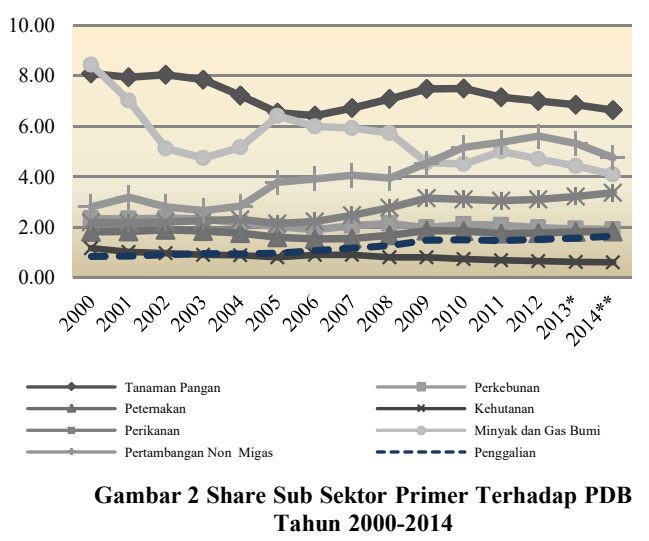

Pada sisi lain, jika dibandingkan antar berbagai sub sektor primer, sebagaimana Gambar 2 tampak bahwa share tertinggi dimiliki oleh sub sektor tanaman pangan, selanjutnya sub sektor minyak dan gas bumi, serta pertambangan non migas. Sub sektor tanaman pangan dan minyak dan gas bumi menunjukkan kondisi share yang sangat fluktuatif. Adapun share sub sektor perikanan menunjukkan pola yang meningkat, namun mengalami penurunan pada tahun 2005, 2009-2011. Setelah tahun 2011, share sub sektor perikanan mengalami kecenderungan meningkat. Adapun peningkatan rata-rata sub sektor perikanan selama periode penelitian 2010-2014 (Tabel 2) yaitu sebesar 0,07 persen. Sementara pertumbuhan sub sektor perikanan secara nasional juga mengalami kecenderungan meningkat, mendekati 7 persen pada tahun 2014.

Tabel 2 Pertumbuhan dan Share Sub Sektor Perikanan Tahun 2010-2014

\begin{tabular}{|ccc|}
\hline Tahun & Pertumbuhan & Share \\
\hline $\mathbf{2 0 1 0}$ & 6.04 & 3.09 \\
\hline $\mathbf{2 0 1 1}$ & 6.96 & 3.06 \\
\hline $\mathbf{2 0 1 2}$ & 6.49 & 3.10 \\
\hline $\mathbf{2 0 1 3 *}$ & 6.86 & 3.21 \\
\hline $\mathbf{2 0 1 4 * *}$ & 6.97 & 3.37 \\
\hline Rata-rata & 6.66 & 3.17 \\
\hline Perubahan rata-rata & 0,07 \\
\hline \\
*angka sementara; ** angka sangat sementara \\
Sumber: BPS 2015
\end{tabular}

Kawasan Konservasi Perairan Wilayah Pesisir

Kawasan konservasi perairan Indonesia berada dibawah koordinasi Kementrian Kehutanan; dan Kementrian Kelautan dan Perikanan. Kawasan konservasi inisiasi Kementrian Kehutanan yaitu: Taman Nasional Laut, Taman Wisata Alam Laut, Suaka Margasatwa Laut, dan Cagar Alam Laut. Kawasan konservasi perairan dibawah KKP terdiri dari Taman Nasional Perairan, Suaka Alam Perairan, Taman Wisata Perairan dan Kawasan Konservasi Perairan Daerah. Adapun Komposisi persentase luasan berdasarkan Jenis konservasi perairan disajikan 
sebagaimana Gambar 3 yang menunjukkan bahwa Kawasan Konservasi perairan Daerah merupakan kawasan terluas setelah Taman Laut Nasional, dengan luas kawasan pada tahun 2013 mencapai lebih dari 5 juta hektar; sementara Taman Laut Nasional memiliki luas lebih dari 4 juta hektar.

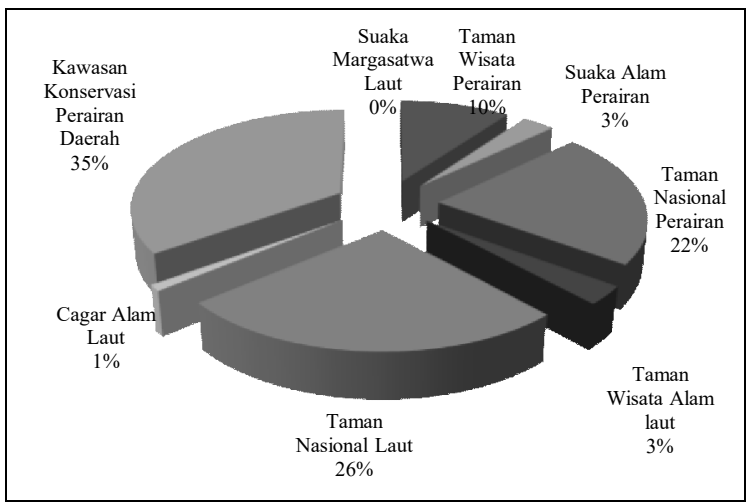

Sumber: KKP (2013) hal 6

\section{Gambar 3 Komposisi Persentase Luasan berdasarkanJenis KKP di Indonesia}

Kawasan Konservasi Perairan yang diinisiasi oleh Kementrian Kelautan dan Perikanan bersama dengan pemerintah daerah hingga akhir tahun 2014 berada pada 98 kabupaten; dengan 103 kawasan yang tersebar pada seluruh propinsi di Indonesia (kecuali Propinsi DKI Jakarta, Sumatera Selatan, dan Kalimantan Tengah) sebagaimana disajikan pada Tabel 3.

Tabel 3 Jumlah Kawasan Konservasi Perairan Kementrian KKP Berdasarkan Propinsi

\begin{tabular}{llcclc}
\hline No & \multicolumn{1}{c}{ Propinsi } & Jumlah & No & \multicolumn{1}{c}{ Propinsi } & Jumlah \\
\hline $\mathbf{1}$ & Aceh & 4 & $\mathbf{1 7}$ & $\begin{array}{l}\text { Nusa Tenggara } \\
\text { Timur }\end{array}$ & 3 \\
\hline $\mathbf{2}$ & Sumatera Utara & 4 & $\mathbf{1 8}$ & Kalimantan Barat & 1 \\
\hline $\mathbf{3}$ & Sumatera Barat & 9 & $\mathbf{1 9}$ & Kalimantan Selatan & 2 \\
\hline $\mathbf{4}$ & Riau & 1 & $\mathbf{2 0}$ & Kalimantan Timur & 2 \\
\hline $\mathbf{5}$ & Jambi & 2 & $\mathbf{2 1}$ & Kalimantan Utara & 2 \\
\hline $\mathbf{6}$ & Bengkulu & 3 & $\mathbf{2 2}$ & Sulawesi Utara & 3 \\
\hline $\mathbf{7}$ & Lampung & 2 & $\mathbf{2 3}$ & Gorontalo & 2 \\
\hline $\mathbf{8}$ & Bangka Belitung & 5 & $\mathbf{2 4}$ & Sulawesi Tengah & 2 \\
\hline $\mathbf{9}$ & Riau Kepulauan & 5 & $\mathbf{2 5}$ & Sulawesi Barat & 2 \\
\hline $\mathbf{1 0}$ & Banten & 1 & $\mathbf{2 6}$ & Sulawesi Selatan & 4 \\
\hline $\mathbf{1 1}$ & Jawa Barat & 3 & $\mathbf{2 7}$ & Sulawesi Tenggara & 5 \\
\hline $\mathbf{1 2}$ & Jawa Tengah & 5 & $\mathbf{2 8}$ & Maluku Utara & 5 \\
\hline $\mathbf{1 3}$ & DI Yogyakarta & 2 & $\mathbf{2 9}$ & Maluku & 1 \\
\hline $\mathbf{1 4}$ & Jawa Timur & 4 & $\mathbf{3 0}$ & Papua Barat & 3 \\
\hline $\mathbf{1 5}$ & Bali & 3 & $\mathbf{3 1}$ & Papua & 1 \\
\hline $\mathbf{1 6}$ & Nusa Tenggara & 7 & & & \\
\hline & Barat & & & & \\
\hline Sum & ber: Kelautan & Perikanan & \\
\hline
\end{tabular}

Sumber: Kelautan dan Perikanan dalam Angka (2014) hal 155-164, disusun kembali
Pertumbuhan Sub Sektor Perikanan Wilayah Pesisir

Tabel 4 menyajikan pertumbuhan ekonomi dan pertumbuhan sub sektor perikanan masing-masing wilayah penelitian periode 2011-2014. Hanya Lampung Barat yang mengalami pertumbuhan negatif dengan nilai ratarata pertumbuhan yang negatif 3,87 persen. Pertumbuhan ekonomi tertinggi dialami oleh Kabupaten Pangkajene Kepulauan sebesar 9,40 persen, disusul oleh Kabupaten Nunukan dan Kabupaten Muna.

Pada sisi lain, untuk pertumbuhan sub sektor perikanan tampak bahwa Kabupaten Muna dan Luwu Utara merupakan kabupaten dengan pertumbuhan tertinggi untuk sub sektor perikanan, bahkan nilainya melebihi pertumbuhan ekonomi total pada wilayah tersebut. Sehingga rasio antara pertumbuhan sub sektor terhadap pertumbuhan ekonomi lebih besar dari satu (atau >1). Beberapa kabupaten lain yang memiliki rasio lebih besar $>1$ yaitu Kabupaten Simeulue, Kabupaten Pesisir Selatan, Kabupaten Natuna, dan Kabupaten Minahasa Selatan. Sementara sebanyak 17 kabupaten memiliki pertumbuhan subsektor perikanan yang lebih rendah jika dibandingkan dengan pertumbuhan ekonomi wilayahnya. Nilai rasio pertumbuhan sub sektor perikanan yang lebih rendah menunjukkan bahwa pada kabupaten tersebut, pertumbuhan sub sektor perikanan tumbuh lebih lambat di banding rata-rata seluruh sektor.

Jika dibandingkan dengan pertumbuhan rata-rata sub sektor perikanan secara nasional sebesar 6,66 persen sebagaiama Tabel 2 maka tampak bahwa hanya terdapat 2 kabupaten yang memiliki pertumbuhan lebih tinggi dibanding rata-rata nasional, yaitu: Kabupaten Luwu Utara dan Kabupaten Muna sebesar 8,45 persen. 
Tabe1 4 Rata-rata Pertumbuhan Ekonomi dan Sub Sektor Perikanan 2010-2014

\begin{tabular}{llrrc}
\hline No & Kabupaten & $\begin{array}{c}\text { Growth } \\
\text { Total }\end{array}$ & $\begin{array}{c}\text { Growth } \\
\text { Perikanan }\end{array}$ & Rasio \\
\hline $\mathbf{1}$ & Simeulue & 4.79 & 5.07 & 1.06 \\
\hline $\mathbf{2}$ & Aceh Jaya & 4.20 & 2.28 & 0.54 \\
\hline $\mathbf{3}$ & Aceh Besar & 3.69 & na & na \\
\hline $\mathbf{4}$ & Sabang & 4.05 & 2.35 & 0.58 \\
\hline $\mathbf{5}$ & Serdang Bedagai & 5.77 & na & na \\
\hline $\mathbf{6}$ & Pesisir Selatan & 5.79 & 5.81 & 1.00 \\
\hline $\mathbf{7}$ & Pariaman & 6.03 & 5.58 & 0.92 \\
\hline $\mathbf{8}$ & Pasaman Barat & 6.28 & 5.88 & 0.94 \\
\hline $\mathbf{9}$ & Kaur & 5.04 & 4.17 & 0.83 \\
\hline $\mathbf{1 0}$ & Mukomuko & 6.28 & 3.29 & 0.52 \\
\hline $\mathbf{1 1}$ & Lampung Barat & -3.87 & na & na \\
\hline $\mathbf{1 2}$ & Bintan* & 7.00 & 6.57 & 0.93 \\
\hline $\mathbf{1 3}$ & Natuna & 4.62 & 5.53 & 1.20 \\
\hline $\mathbf{1 4}$ & Lingga** & 6.64 & 2.84 & 0.43 \\
\hline $\mathbf{1 5}$ & Tegal & 5.84 & 3.30 & 0.56 \\
\hline $\mathbf{1 6}$ & Brebes & 6.13 & 4.71 & 0.77 \\
\hline $\mathbf{1 7}$ & Klungkung & 6.10 & na & na \\
\hline $\mathbf{1 8}$ & Dompu & 6.15 & 4.60 & 0.75 \\
\hline $\mathbf{1 9}$ & Bima & 5.91 & 4.74 & 0.80 \\
\hline $\mathbf{2 0}$ & Bengkayang & 5.22 & 2.65 & 0.51 \\
\hline $\mathbf{2 1}$ & Nunukan & 8.12 & na & na \\
\hline $\mathbf{2 2}$ & Minahasa Selatan & 5.82 & 5.97 & 1.03 \\
\hline $\mathbf{2 3}$ & Bone Bolango & 7.44 & na & na \\
\hline $\mathbf{2 4}$ & Pangkajene & 9.40 & 6.51 & 0.69 \\
& Kepulauan & & & \\
\hline $\mathbf{2 5}$ & Luwu Utara & 7.68 & 8.45 & 1.10 \\
\hline $\mathbf{2 6}$ & Muna & 8.00 & 8.45 & 1.06 \\
\hline $\mathbf{2 7}$ & Sorong & 5.89 & na & na \\
\hline $\mathbf{2 8}$ & Raja Ampat & 3.98 & 2.80 & 0.70 \\
\hline $\mathbf{2 9}$ & Kaimana & 6.48 & 1.60 & 0.25 \\
\hline $\mathbf{3 0}$ & Biak Numfor & 5.91 & 4.22 & 0.72 \\
\hline $\mathbf{2 0 1 2 - 2 0 1 4 ; * * ~ 2 0 1 3 - 2 0 1 4 ~}$ & & & \\
$\mathbf{S u m}$ & & & \\
\hline
\end{tabular}

Sumber: BPS berbagai tahun, diolah

\section{Share Sub Sektor Perikanan Wilayah Pesisir}

Salah atu indikator berkembangnya sub sektor perikanan yaitu seberapa besar kontribusi sektor tersebut dalam perekonomian, dan apakah kontribusi tersebut secara konsisten mengalami peningkatan. Tabel 5 menyajikan share sub sektor perikanan masing-masing kabupaten yang teliti, dan menunjukkan bahwa Kabupaten Raja Ampat merupakan Kabupaten Pesisir dengan share perikanan tertinggi sebesar 30,56 persen; disusul Kabupaten Biak Numfor dan Kabupaten Kaur. Beberapa kabupaten lain yang memiliki kontribusi cukup besar atau diatas
10 persen yaitu: Kabupaten Simeulue, Mukomuko, Lingga, Muna, Pangkajene Kepulauan, Sorong dan Kaimana.

Pada sisi lain jika dibandingkan dengan share rata-rata sub sektor perikanan secara nasional selama kurun waktu 2010-2014 sebesar 3,17 persen (Tabel 2), maka tampak bahwa sebanyak 7 kabupaten yang menjadi kawasan konservasi sejak 2010 bukan merupakan sektor basis bagi perikanan Indonesia, yang ditunjukkan dengan share perikanan yang lebih rendah dibanding share secara nasional. Kabupaten tersebut yaitu: Aceh Jaya, Aceh Besar, Sabang, Lampung Barat, Tegal, Brebes dan Bengkayang. Hal ini menunjukkan bahwa kawasan konservasi belum sepenuhnya menjadi wilayah basis sub sektor perikanan.

Tabel 4 juga menyajikan bahwa dari 30 kabupaten yang diteliti, tampaknya sebanyak 18 kabupaten mengalami penurunan share selama kurun waktu 2011-2014. Total penurunan share rata-rata sebesar 12,83 persen; atau mengalami penurunan pertahun sebesar 3,21 persen. Hal ini mengimplikaikan bahwa, jika penurunan share terus terjadi pada kawasan konservasi perairan yang justru bertujuan untuk mendorong sub sektor perikanan jangka panjang, maka diperlukan strategi yang riil guna peningkatan kontibusinya. Sebab kondisi kawasan konservasi justru bertolak belakang dengan kondisi share perikanan secara nasional. Pada Tabel 2 tampak bahwa share sub sektor perikanan secara nasional periode 2010-2014 secara cenderung mengalami peningkatan sebesar 0,07 persen.

Adapun kabupaten yang mengalami penurunan share tertinggi yaitu Kabupaten Kaimana sekitar 5 persen; kemudian Kabupaten Lampung Barat dan Natuna, yang masing-masing mengalami penurunan share sebesar 2,30 persen dan 2,28 persen. Beberapa kabupaten yang mengalami peningkatan 
share yaitu: Kabupaten Serdang Bedagai, Pesisir Selatan, Pariaman, Pasaman Barat, Kaur, Brebes, Nunukan, Minahasa Selaten, Bone Bolango, Luwu Utara dan Muna.

Tabel 5 Share Sub Sektor Perikanan, Perubahan Share dan Rasio Terhadap Share Nasional 2011-2014

\begin{tabular}{|c|c|c|c|c|}
\hline No & Kabupaten & $\begin{array}{c}\text { Share } \\
\text { Rata-rata }\end{array}$ & $\begin{array}{l}\text { Penurunan/ } \\
\text { Peningkatan }\end{array}$ & $\begin{array}{c}\text { Rasio } \\
\text { Terhadap } \\
\text { Share } \\
\text { Nasional }\end{array}$ \\
\hline 1 & Simeulue & 11.91 & -0.130 & Tinggi \\
\hline 2 & Aceh Jaya & 2.13 & -0.062 & Rendah \\
\hline 3 & Aceh Besar & 3.01 & -0.145 & Rendah \\
\hline 4 & Sabang & 2.3 & 0.000 & Rendah \\
\hline 5 & Serdang Bedagai & 5.62 & 0.370 & Tinggi \\
\hline 6 & Pesisir Selatan & 5.9 & 0.280 & Tinggi \\
\hline 7 & Pariaman & 8.99 & 0.450 & Tinggi \\
\hline 8 & Pasaman Barat & 4.31 & 0.180 & Tinggi \\
\hline 9 & Kaur & 18.05 & 1.180 & Tinggi \\
\hline 10 & Mukomuko & 16.02 & -1.240 & Tinggi \\
\hline 11 & Lampung Barat & 2.32 & -2.300 & Rendah \\
\hline 12 & Bintan & 3.82 & -0.254 & Tinggi \\
\hline 13 & Natuna & 30.30 & -2.280 & Tinggi \\
\hline 14 & Lingga & 13.82 & -1.343 & Tinggi \\
\hline 15 & Tegal & 0.61 & -0.040 & Rendah \\
\hline 16 & Brebes & 2.62 & 0.040 & Rendah \\
\hline 17 & Klungkung & 9.57 & -0.962 & Tinggi \\
\hline 18 & Dompu & 7.29 & -0.700 & Tinggi \\
\hline 19 & Bima & 9.26 & -0.990 & Tinggi \\
\hline 20 & Bengkayang & 2.68 & -0.410 & Rendah \\
\hline 21 & Nunukan & 6.79 & 3.070 & Tinggi \\
\hline 22 & Minahasa Selatan & 6.59 & 1.070 & Tinggi \\
\hline 23 & Bone Bolango & 8.33 & 1.291 & Tinggi \\
\hline 24 & Pangkajene Kepulauan & 11.27 & -1.120 & Tinggi \\
\hline 25 & Luwu Utara & 9.77 & 1.500 & Tinggi \\
\hline 26 & Muna & 11.97 & 1.020 & Tinggi \\
\hline 27 & Sorong & 10.55 & -2.208 & Tinggi \\
\hline 28 & Raja Ampat & 30.56 & -2.150 & Tinggi \\
\hline 29 & Kaimana & 16.84 & -4.980 & Tinggi \\
\hline 30 & Biak Numfor & 21.39 & -1.970 & Tinggi \\
\hline \multicolumn{2}{|r|}{ Total } & & $-12,833$ & \\
\hline
\end{tabular}

Sumber: BPS berbagai tahun, diolah

\section{Akselerasi Pertumbuhan Wilayah Pesisir}

Akselerasi pertumbuhan sub sektor perikanan diperoleh melalui pemetaan pertumbuhan dan share sub sektor perikanan sebagaimana disajikan pada Tabel 4 dan 5. Berdasarkan ketersediaan data, maka hanya 23 kabupaten yang diolah lebih lanjut. Hasil pemetaan kembali Tabel 4 dan Tabel 5 disajikan sebagaimana Gambar 4 yang menunjukkan bahwa dari total kabupaten yang diolah, hanya 4 kabupaten yang menunjukkan pertumbuhan sub sektor perikanan yang tinggi sekaligus mengalami peningkatan share bidang perikanan. Kabupaten tersebut yaitu: Kabupaten Pesisir Selatan, Minahasa Selatan, Luwu Utara dan Muna. Gambar 4 juga menunjukkan 50 persen lebih kabupaten atau sebanyak 12 kabupaten menunjukkan wilayah rentan kemunduran bidang perikanan.

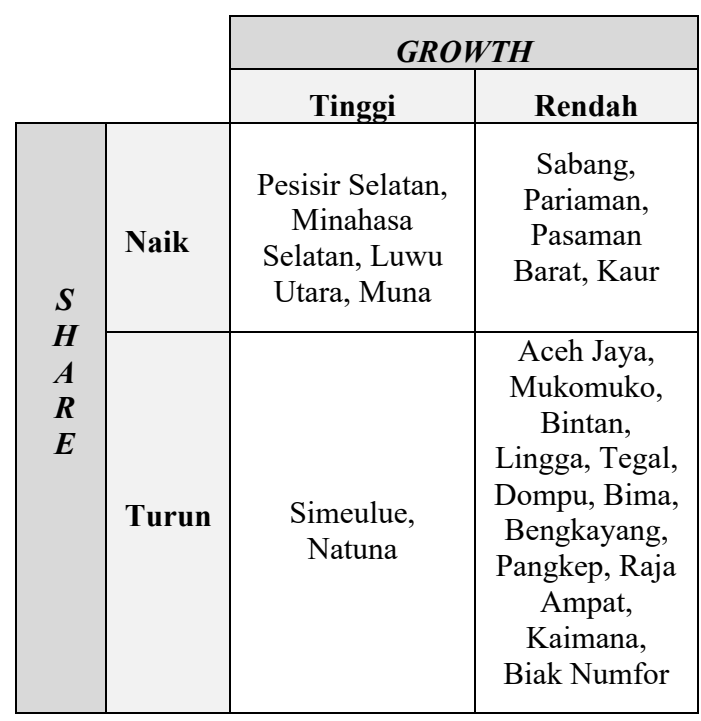

Sumber: Tabel 4 dan Tabel 5, disusun kembali

Gambar 4

Peta Akselerasi Pertumbuhan Ekonomi Subsektor Perikanan Kabupaten Pesisir Indonesia

\section{Implikasi}

Temuan penelitian menunjukkan bahwa mayoritas kabupaten yang telah mengembangkan kawasan konservasi perikanan sekitar 5 tahun justru mengalami rentan kemunduran sub sektor perikanan. Hanya empat kabupaten yang menunjukkan akselerasi. Dari 12 kabupaten yang mengalami rentan kemunduruan terdapat kabupaten yang telah menjalankan peogram kawasan konservasi perikanan kurang lebih satu dekade, yaitu: Kabupaten Lingga sejak tahun 2002; Kabupaten Bengkayang sejak tahun 2004; dan Kabupaten Bima pada tahun 2005.

Temuan ini berbeda dengan temuan Claudet et al.(2006) yang melakukan penelitian pada kawasan konservasi 
Mediterania Barat Laut (Northwestern Mediterranean). Dengan membandingkan kondisi sebelum dan pasca konservasi, ditemukan bahwa populasi ikan lebih melimpah disertai dengan peningkatan keanekaragaman jenis ikan di dalam kawasan pasca konservasi. Green and Kilarski (2013) mengungkapkan bahwa jika kawasan konservasi dikelola dengan baik, maka akan mengurangi ancaman lokal, mempertahankan spesies rentan dari ancaman perubahan iklim dan berkontribusi terhadap stabilitas perikanan jangka panjang.

Tentunya banyak faktor yang mempengaruhi keberhasilan program konservasi perikanan, baik dari aspek finansial, masyarakat lokal maupun pengelola sendiri. Pengelolaan kawasan konservasi perlu dilakukan secara terpadu dan melibatkan seluruh pihak yang berkepentingan dengan langkah-langka strategis yang lebih tepat, yang tidak mengorbankan kepentingan antar generasi sehingga kawasan konservasi perikanan menjadi solusi tepat atas akselerasi bagi pertumbuhan ekonami sekaligus bagi kepentingan ekonomi jangka panjang.

\section{KESIMPULAN}

Hasil penelitian menunjukkan bahwa sebanyak 7 kabupaten yang diteliti bukan merupakan sektor basis perikanan bagi Indonesia yang ditunjukkan dengan nilai share sub sektor perikanan yang lebih rendah dibanding share nasional. Kabupaten tersebut yaitu: Aceh Jaya, Aceh Besar, Sabang, Lampung Barat, Tegal, Brebes dan Bengkayang. Secara umum seluruh kabupaten mengalami pertumbuhan dalam sektor perikanan, namun 17 kabupaten diantaranya memiliki pertumbuhan yang lebih rendah dibanding pertumbuhan ekonomi wilayahnya. Pada sisi lain, terdapat kecenderungan penurunan share selama tahun yang secara total rata-rata pertahun sebesar 3,21 persen. Penurunan share terjadi pada 18 kabupaten. Hasil penelitian juga menunjukkan bahwa hanya 4 kabupaten yang mengalami akselerasi pertumbuhan, bahkan sebanyak 12 kabupaten berada pada wilayah rentan kemunduran pada sektor perikanan.

Penelitian ini memiliki keterbatasan untuk mengungkap apakah ada pengaruh program konservasi perikanan terhadap penurunan share sub sektor perikanan. Diharapkan peneliti selanjutnya dapat mengkaji akselerasi pertumbuhan dengan membandingkan sebelum dan setelah program konservasi, serta mengkaji variabel-variabel penentu akselerasi pertumbuhan sub sektor perikanan khususnya; dan sektor maritim secara luas.

\section{REFERENSI}

BPS (2015) Distribusi Produk Domestik Regional Bruto Berdasarkan Lapangan Usaha.Tersedia pada http://bps.go.id

BPS Aceh Besar (2015) Produk Domestik Regional Bruto Kabupaten Aceh Besar Menurut Lapangan Usaha 2010-2014. BPS Kabupaten Aceh Besar. Tersedia pada: http://acehbesarkab.bps.go.id

BPS Aceh Jaya (2015) Produk Domestik Regional Bruto Kabupaten Aceh Jaya Menurut Lapangan Usaha 2010-2014. BPS Kabupaten Aceh Jaya. Tersedia pada: http://acehjayakab.bps.go.id

BPS Bengkayang (2015) Produk Domestik Regional Bruto Kabupaten Bengkayang Menurut Lapangan Usaha 2010-2014. BPS Kabupaten Bengkayang. Tersedia pada: http://bengkayangkab.bps.go.id

BPS Biak Numfor (2015) Produk Domestik Regional Bruto Kabupaten Biak Numfor 2015. BPS Kabupaten Biak Numfor. Tersedia pada: http://biaknumforkab.bps.go.id

BPS Bima (2015) Produk Domestik Regional Bruto Kabupaten Bima 
Menurut Lapangan Usaha 2010-2014. BPS Kabupaten Bima. Tersedia pada: http://bimakab.bps.go.id

BPS Bintan (2015) Produk Domestik Regional Bruto Kabupaten Bintan Menurut Lapangan Usaha 2010-2014. BPS Kabupaten Bintan. Tersedia pada: http://bintankab.bps.go.id

BPS Bone Bolango (2015) Produk

Domestik Regional Bruto Kabupaten

Bone Bolango Menurut Lapangan Usaha 2010-2014. BPS Kabupaten Bone Bolango. Tersedia pada: http://bonebolangokab.bps.go.id

BPS Brebes (2015) PDRB Kabupaten Brebes Menurut Lapangan Usaha 2014. BPS Kabupaten Brebes. Tersedia pada: http://brebeskab.bps.go.id

BPS Dompu (2015) Produk Domestik Regional Bruto Kabupaten Dompu Menurut Lapangan Usaha 2010-2014. BPS Kabupaten Dompu. Tersedia pada: http://dompukab.bps.go.id

BPS Kaimana (2015) Produk Domestik Regional Bruto Kabupaten Kaimana Menurut Lapangan Usaha 2014. BPS Kabupaten Kaimana. Tersedia pada: http://kaimanakab.bps.go.id

BPS Kaur (2015) Produk Domestik Regional Bruto Kabupaten Kaur Menurut Lapangan Usaha 2010-2014. BPS Kabupaten Kaur. Tersedia pada: http://kaurkab.bps.go.id

BPS Klungkung (2015) Produk Domestik Regional Bruto Kabupaten Klungkung Menurut Lapangan Usaha 2010-2014. BPS Kabupaten Klungkung. Tersedia pada: http://klungkungkab.bps.go.id

BPS Lampung Barat (2015) Produk Domestik Regional Bruto Kabupaten Lampung Barat Menurut Lapangan Usaha 2010-2014. BPS Kabupaten Lampung Barat. Tersedia pada: http://lampungbaratkab.bps.go.id

BPS Lingga (2015) Produk Domestik Regional Bruto Kabupaten Lingga Menurut Lapangan Usaha 2010-2014. BPS Kabupaten Lingga. Tersedia pada: http://linggakab.bps.go.id
BPS Luwu Utara (2015) Produk Domestik Regional Bruto 20102014Menurut Lapangan Usaha Kabupaten Luwu Utara. Tersedia pada: http://luwuutarakab.bps.go.id

BPS Minahasa Selatan (2015) Produk Domestik Regional Bruto Kabupaten Minahasa Selatan Menurut Lapangan Usaha 2010-2014. BPS Kabupaten Minahasa Selatan. Tersedia pada: http://minselkab.bps.go.id

BPS Mukomuko (2015) Produk Domestik Regional Bruto Kabupaten Mukomuko Menurut Lapangan Usaha 2010-2014. BPS Kabupaten Mukomuko. Tersedia pada: http://mukomukokab.bps.go.id

BPS Muna (2015) Produk Domestik Regional Bruto Menurut Lapangan Usaha Kabupaten Muna 2010-2014. BPS Muna. Tersedia pada: http://munakab.bps.go.id

BPS Nunukan (2015) Produk Domestik Regional Bruto Kabupaten Nunukan Menurut Lapangan Usaha 20102014. BPS Kabupaten Nunukan. Tersedia pada: http://nunukankab.bps.go.id

BPS Natuna (2015) Produk Domestik Regional Bruto Kabupaten Natuna Menurut Lapangan Usaha 20102014. BPS Kabupaten Natuna. Tersedia pada: http://natunakab.bps.go.id

BPS Pangkep (2015) Produk Domestik Regional Bruto Kabupaten Pangkajene Kepulauan Menurut Lapangan Usaha 2010-2014. BPS Kabupaten Pangkajene Kepulauan. Tersedia pada: http://pangkepkab.bps.go.id

BPS Pariaman (2015) Produk Domestik Regional Bruto Kota Pariaman Menurut Lapangan Usaha 20102014. BPS Kota Pariaman. Tersedia pada: http://pariamankota.bps.go.id

BPS Pasaman Barat (2015) Produk Domestik Regional Bruto Kabupaten 
Pasaman Barat Menurut Lapangan Usaha 2010-2014. BPS Kabupaten Pasaman Barat. Tersedia pada: http://pasamanbaratkab.bps.go.id

BPS Pesisir Selatan (2015) Produk Domestik Regional Bruto Menurut Lapangan Usaha Kabupaten Pesisi Selatan 2010-2014. BPS Kabupaten Pesisir Selatan. Tersedia pada: http://pesselkab.bps.go.id

BPS Raja Ampat (2015) Produk Domestik Regional Bruto Kabupaten Raja Ampat Menurut Lapangan Usaha 2010-2014. BPS Kabupaten Raja Ampat. Tersedia pada: http://rajaampatkab.bps.go.id

BPS Sabang (2015) Produk Domestik Regional Bruto Kota Sabang Menurut Lapangan Usaha 2010-2014. BPS Kota Sabang. Tersedia pada: http://sabangkota.bps.go.id

BPS Serdang Bedagai (2015) Produk Domestik Regional Bruto Kabupaten Serdang Bedagai Menurut Lapangan Usaha 2010-2014. BPS Kabupaten Serdang Bedagai. Tersedia pada: http://serdangbedagaikab.bps.go.id

BPS Simeulue (2015) Produk Domestik Regional Bruto Kabupaten Simeulue Menurut Lapangan Usaha 2010-2014. BPS Kabupaten Simeulue. Tersedia pada: http://simeuleukab.bps.go.id

BPS Sorong (2015) Produk Domestik Regional Bruto Kabupaten Sorong Menurut Lapangan Usaha 2010-2014. BPS Kabupaten Sorong. Tersedia pada: http://sorongkab.bps.go.id

BPS Tegal (2015) Produk Domestik Regional Bruto Kabupaten Tegal Menurut Lapangan Usaha 2010-2014. BPS Kabupaten Tegal. Tersedia pada: http://tegalkab.bps.go.id

Claudet, et al (2006). Assessing the Effects of Marine Protected Area (MPA) on a Reef Fish Assemblage In a Northwestern Mediterranean Marine Reserve: Identifying Com- munityBased Indicators. Biological Conservation, $130: 349-369$.

Green, A., White, A. and Kilarski, S. (Eds.)
(2013). Designing Marine Protected Area Networks to Achieve Fisheries, Biodiversity, and Climate Change Objectives in Tropical Ecosystems: a Practitioner Guide. The Nature Conservancy and the USAID Coral Triangle Support Partnership, Cebu City, Philippines.

Kementrian Kelautan dan Perikanan (2013) Informasi Kawasan Konservasi Perairan Indonesia. Direktoran Jenderal Kelautan, Pesisir, dan Pulau-pulau Kecil

Kementrian Kelautan dan Perikanan (2014a) Kelautan dan Perikanan dalam Angka Tahun 2014. Pusat Data Statistik dan Informasi Kementrian Kelautan dan Perikanan

Kementrian Kelautan dan Perikanan (2014b) Peraturan Menteri Perikanan dan Kelautan No 13 Tahun 2014 Tentang Jejaring Kawasan Konservasi Perairan

Susanto, H.A. (2011). Progres Pengembangan Sistem Kawasan Konservasi PerairanIndonesia: A Consultancy Report. Kerjasama Kementerian Kelautan dan Perikanan dengan Coral Triangle Support Partnership (CTSP)

Wibowo, Adi (2012) Kerentanan Lingkungan Laut Tiap Provinsi di Indonesia, Jurnal Ilmu dan Teknologi Kelautan Tropis, Vol. 4 (1):145-162 